\title{
The role of personality traits in green decision-making
}

\author{
Ante Busic-Sontic ${ }^{* a}$ \\ Natalia V. Czap ${ }^{\mathrm{b}}$ \\ Franz Fuerst ${ }^{\text {ac }}$
}

*Corresponding author: ab2242@cam.ac.uk

a University of Cambridge, Department of Land Economy, Cambridge CB3 9EP, UK

b University of Michigan-Dearborn, Department of Social Sciences (Economics) and Behavioral \& Experimental Economics \& Policy Laboratory, Dearborn, MI, USA c University of Melbourne, Thrive Research Hub, Melbourne, VIC 3010, Australia 


\begin{abstract}
This paper investigates whether personality traits play a significant role in the decision to invest in energy efficiency in the residential sector. Using the data from the Understanding Society UK survey, we apply structural equation modelling to examine if the Big Five personality traits help explain why certain individuals choose to invest in energy efficiency measures while others do not, even under nearly identical financial conditions. The results show that personality traits affect one-time, high-cost energy efficiency investments indirectly through environmental attitudes and risk preferences. However, low-cost proenvironmental habits, such as conserving energy and buying 'green' products, are mediated only through the environmental attitude, but not through the risk preference channel. This is consistent with the fact that these everyday choices carry a much lower financial risk than an expensive energy efficiency investment. The findings illustrate that personality traits may pose a barrier to reducing energy consumption in the residential sector and underline the need for creating differentiated and targeted products and policies.
\end{abstract}

Keywords: Energy efficiency; Pro-environmental behaviour; Personality traits, Risk preferences; Environmental concern; Residential sector 


\section{Introduction}

By signing the Paris Agreement on Climate Change of $2015^{1}$, the UK along with other countries has agreed to limit the rise in global temperature to well below $2{ }^{\circ} \mathrm{C}$ above pre-industrial levels (UNFCCC, 2015). To achieve this goal, the Agreement sets out a target of net zero greenhouse gas emissions in the second half of the $21^{\text {st }}$ century. In 2014 , residential buildings accounted for $22 \%$ of total UK greenhouse gas emissions (Committee on Climate Change, 2014). Improving energy efficiency (EE) in homes offers a promising route towards achieving the emissions reduction goals along with smaller and cheaper-toimplement changes such as conserving energy and using public transport.

It has been estimated that by 2020 about 10 million homes in the UK will have solar panels on their roofs (Harvey, 2014). However, the uptake of sustainable and EE measures remains moderate despite their apparent financial profitability and benefits to environment. Stern et al. (2016) stressed the importance of considering behavioural and social factors to close the gap between potential and realised EE measures ("EE gap"). In this paper, we pick up their suggestion and show empirically that a homeowner's economic decision to invest in EE can be partially predicted by certain personality traits of the decision-maker. We also compare EE investments to pro-environmental behaviour and find similar results in terms of personality traits and environmental attitudes. However, risk preferences and household income levels are more important for predicting EE investments, which entail larger financial outlays than pro-environmental behaviour (PEB).

It is well documented that market failures such as imperfect information or unpriced externalities can prevent optimal allocation of resources into EE (Gerarden et al., 2015; Bardhan et al., 2014). More recently, researchers have turned to behavioural approaches for explaining suboptimal EE investment decisions (Ramos et al., 2015a; Allcott and

\footnotetext{
${ }^{1}$ The Paris Agreement was adopted in December 2015 and entered into force in November 2016.
} 
Mullainathan, 2010). Gerarden et al. (2015) pointed out several behavioural anomalies (e.g. inattention, loss aversion, and myopia) that are responsible for the EE gap. In the residential sector, researchers have found that differences in social norms do matter for energy saving behaviour (Allcott and Rogers, 2014). It has been also shown that households with proenvironmental habits are more likely to invest into energy-efficient appliances (Ramos et al. 2015b). To our knowledge, this paper presents the first empirical attempt to predict EE investments using data on individual psychological characteristics (personality traits). Specifically, a structural equation model (SEM) is estimated using data on UK homeowners, to predict solar and wind turbine installations for electricity generation and solar water heating. The findings are compared to PEB by applying the same model to environmental habits (e.g. switching off appliances when not in use, carpooling, and using public transport). The results contribute to a better understanding of the EE gap and why providing financial support or information about EE options may not be sufficient for achieving higher levels of EE in the residential sector in line with carbon emissions targets.

\section{Heterogeneous consumers and the EE gap}

A number of studies investigating the microeconomic determinants of EE investments try to explain why some households choose to invest while others do not, even under seemingly identical financial circumstances (Ramos et al., 2015a; Allcott et al., 2014). Two factors emerge as particularly salient.: The EE benefits are uncertain and they will (or not) occur in the future, while costs are certain and occur in the present (Fischbacher et al., 2015). Uncertainty arises from the fluctuation of energy prices as well as from idiosyncratic factors (e.g. household energy demand may fall in the future). In addition, consumers' beliefs as well as cultural and ideological factors may be of importance (Ramos et al., 2015a). If the heterogeneity energy consumers is ignored, the estimated energy saving potential might be biased upwards and the EE gap may be overstated (Gerarden et al., 2015). 
Several empirical studies of the residential sector provide evidence that environmental attitudes, environmental concern, and PEB influence the use of energy and households' EE. Ramos et al. (2015b) find that eco-friendly behaviour (e.g. recycling) among Spanish households is associated with higher investments into energy-efficient appliances, lowconsumption bulbs and double glazing. Lange et al. (2014) show the evidence of a positive relationship between a set of $\mathrm{PEB}$, such as wearing a jumper instead of increasing the thermostat settings, and heating expenditures in the UK.

Although researchers observe heterogeneity among energy consumers, little is known about the causes for these differences. One of the possible explanations of heterogeneity is the variation in the individual psychological characteristics, specifically personality traits. Numerous studies show that personality traits affect investor's behaviour and certain economic outcomes, including employment status and wages, household's financial asset allocation, and regional entrepreneurship rates (Gherzi et al., 2014; Fletcher, 2013; Brown and Taylor, 2014; Obschonka et al., 2015). Other researchers find significant influence of empathy, locus of control, autism, and selfism (Ovchinnikova et al., 2009), trust and empathy (Czap and Czap, 2010), empathy and selfism (Czap et al., 2012) on conservation behaviour in framed laboratory experiments. In the context of self-reported past behaviour, Brick and Lewis (2014), using a large sample of the U.S. consumers, demonstrate that Openness to Experience, Conscientiousness and Extraversion are associated with environmental attitudes and emission-reducing activities (e.g. using reusable bags, driving below a certain speed on highways, flying for non-business purposes). By investigating electricity conservation activities from 377 individuals in New Zealand (e.g. turning off electric equipment when not in use, using EE appliances, air-drying clothes instead using clothes drier), Milfont and Sibley (2012) find strong links between such behaviour and Conscientiousness, Agreeableness, and Neuroticism, respectively, while the links to Extraversion and Openness 
to Experience are not statistically significant.

Existing studies on personality traits and energy usage focus on energy conservation. Research on personality and EE, however, is remarkably limited. Energy conservation and EE seem to be closely related and previous literature often uses the terms interchangeably, without general agreement on what can be considered energy-efficient ${ }^{2}$. For this research, we take Pérez-Lombard et al.’s (2013) approach and regard passive energy technology (e.g. wall insulation), and energy from renewable resources (e.g. solar electricity, geothermal heating) that is generated "on-site" (i.e. does not have to be delivered to the consumer) and that simultaneously reduces purchased energy, to be energy-efficient. This approach is also in line with the EU and most country-level legislation.

\section{A model for the integration of personality traits into $\mathrm{EE}$ decisions}

We use a modified utility maximisation model for EE based on the work of Allcott and Greenstone (2012) to test the impact of personality traits on EE investments. Consistent with basic financial mathematics, this model assumes that individuals invest into energy efficient technology if discounted savings exceed additional discounted costs. However, the relationship between savings and costs is moderated by individual attitudes and general externalities in the following form:

$$
P V_{\text {Savings }} \times \gamma(\alpha(\Psi), \varphi(\Psi))>P V_{\Delta \text { costs }},
$$

where $\gamma$ is a factor that adjusts the benefits either up or down, depending on the individual's risk attitudes, $\alpha$, and externalities $\varphi$. The variable $\alpha$ expresses individual's propensity to take risks, whereas $\varphi$ describes the degree to which an individual considers environmental and social costs generated by energy production. Importantly, the model assumes that risk preferences $(\alpha)$ and externalities $(\varphi)$, which can be measured with environmental concern, are implicitly a function of personality traits $\Psi$. Hence, personality

\footnotetext{
${ }^{2}$ For a discussion of the terms energy conservation and EE, see Appendix A.
} 
traits $(\Psi)$ are mediated through risk preferences $(\alpha)$ and environmental concern $(\varphi)$ on EE investments. In the same vein, it is assumed that the consumer compares the benefits of PEB, including personal and environmental benefits, with the associated costs, such as effort and time invested (e.g. in recycling) (Young et al., 2010).

The underlying mediation mechanisms for the model are derived from previous research on the links between personality traits on one side and risk preferences and environmental attitudes on the other side. To measure personality traits, we use the Big Five, which is a broadly recognised framework with five core dimensions (Costa and MacCrae, 1992): Openness to Experience, Conscientiousness, Extraversion, Agreeableness and Neuroticism. Researchers have found significant correlations between the Big Five and risk preferences as well as between the Big Five and environmental attitudes. We construct two mediation models: M1 and M2 (Figure 1).

(Insert Figure 1 here)

In M1, we assume a direct effect and two indirect effects through risk preferences and environmental concern (mediators) for each personality trait. In M2, we assume moderated mediation: the mediators can only be translated to EE investments or PEB (e.g. buying more expensive organic products) if households' income is sufficiently high. That is, the translation of the mediators is modelled conditionally on households' relative income (income per household member).

\section{Methods \& derivation of the hypotheses}

Based on the existing risk and environmental attitudes literature, we derive hypotheses for how each of the Big Five traits affects EE investments and PEB (Table 1). Below we introduce each of the Big Five personality traits and discuss their impact on risk preferences and environmental concern.

(Insert Table 1 here) 
Openness to Experience. Openness to Experience $(O)$ is associated with higher willingness to undertake new actions, which very often involve uncertainty. Previous work uncovered strong evidence of a positive relationship between $O$ and risk preferences in the domains such as household asset allocations and entrepreneurship rates (Brown and Taylor, 2014; Obschonka et al., 2013).

As Brick and Lewis (2014) state, flexible and abstract thinking (two main facets of $O$ ) are required to anticipate long-term environmental consequences. Several empirical studies support this causal relationship, reporting a positive correlation between $O$ and environmental concern (Brick and Lewis, 2014; Hilbig et al., 2013; Markowitz et al., 2012; Hirsh and Dolderman, 2007; Hirsh, 2010).

Conscientiousness. Individuals with a high degree of Conscientiousness $(C)$ tend to be responsible and strive for achievement. Such achievement, however, is not aimed at random settings, such as gambling. Rather, the conscientious individuals strive for goal achievement in controlled conditions. This aversion to uncontrollable or uncertain situations is evident in the analysis conducted by Brown and Taylor (2014), who found that households with a high $C$ level have a lower willingness to acquire debts.

Discussions of a causal link between $C$ and environmental concern bring out arguments both in favour of and against pro-environmental engagement (Markowitz et al., 2012). Results from empirical studies show an overall consistent positive relationship, though some show very small influences and minor inconsistencies (Milfont and Sibley, 2012; Hirsh, 2010; Markowitz et al., 2012; Hilbig et al., 2013). Swami et al. (2010) argue that the need for achievement in pro-environmental values explains a positive causal pathway from $C$ to proenvironmental action.

Extraversion. Extraversion $(E)$ directs individual's interest towards the outer world. Individuals who score highly in $E$ values are assertive, ambitious, energetic and optimistic. 
These attributes provide the ability to deal with uncertain decisions. $E$ was found to be a typical characteristic of entrepreneurship-prone individuals, who face a significant level of uncertainty (Zhao et al., 2010; Caliendo et al., 2014). However, previous analyses have found no or only small influence of $E$ on pro-environmental attitudes and therefore, no sign is hypothesised between $E$ and environmental concern (Hirsh, 2010; Milfont and Sibley, 2012; Markowitz et al., 2012).

Agreeableness. People with a high degree of Agreeableness $(A)$ tend to be cooperative and more group- than self-oriented. Individuals with low $A$ tend to be antisocial and egocentric. Self-centered individuals are often inclined towards over-confidence by overestimating their own abilities and knowledge. This can lead to a higher propensity for risk (Chui et al., 2010; Mihet, 2013). Related to environmental concern, several analyses report a robust and positive impact of $A$ on biospheric concern and pro-environmental goals (Hirsh and Dolderman, 2007; Hirsh, 2010; Milfont and Sibley, 2012; Swami et al., 2010).

Neuroticism. Neurotic people tend to be anxious and are susceptible to stress. The literature reports a strong and consistently negative link between Neuroticism $(N)$ and risktaking (Borghans et al., 2009; Zhao et al., 2010). Thus, we hypothesise that $N$ will negatively influence risk preferences.

Results on the link between $N$ and environmental beliefs are mixed, ranging between zero, negative, and positive correlations (Hirsh, 2010; Brick and Lewis, 2014; Markowitz et al., 2012). Hence, no sign is hypothesised for the association between $N$ and environmental concern.

\subsection{EE investment as affected by the Big Five, risk preferences and environmental}

\section{concern}

Because markets for energy-efficient technology are immature, investing in energyefficient technology is associated with significant ambiguity and risk (Ryan et al., 2012). The 
lack of information, and the resulting lack in knowledge about the technology effectiveness and financial profitability among consumers, create defensive attitude towards investments. The expected efficiency benefits may also be uncertain because the technology is new and homeowners' experience from comparable EE projects is limited. Furthermore, the profitability of the investment depends on future energy use and price patterns, which are unknown (Epper et al., 2011; Linares and Labandeira, 2010).

Pro-environmental attitudes and environmental concern, on the other hand, facilitate pro-environmental decisions, including household decisions to adopt energy-efficient technology. Therefore, we hypothesise that higher risk preferences and environmental concern relate positively with EE investments. Consequently, we hypothesise that the Big Five personality traits influence EE investments in the same direction as they affect each of the two mediators.

\subsection{PEB as affected by the Big Five, risk preferences and environmental concern}

This research joins Markowitz et al. (2012, p. 83) in uncovering "underlying, situationally stable factors that motivate individuals to perform many different types of PEB" (pro-environmental behaviour). PEB includes a wide range of individual choices and can be grouped into three categories: (1) routine purchases (e.g. locally-sourced goods, organic or green products, recyclable packaging), (2) environmental habits (e.g. switching off the lights,

putting a sweater instead of adjusting up the thermostat, recycling, using public transport), and (3) environmental engagement (e.g. eco-activism, voluntarism, involvement in environmental organisations). The previous studies demonstrate significant influence of some Big Five traits on PEB (Quintelier, 2014; Markowitz et al., 2012; Milfont and Sibley, 2012; Fraj and Martinez, 2006b).

For the first category, routine purchases, Quintelier (2014) finds that for young people in Belgium Openness to Experience leads to more political consumer behaviour (i.e. 
boycotting environmentally-damaging products and buycotting green or fair-trade products); Conscientiousness and Extraversion lead to less, while Agreeableness and Neuroticism does not influence such behaviour. For the second category, in Study 2 of Milfont and Sibley (2012), conducted in New Zealand, $C, A$ and $N$ are positively associated with home electricity conservation, whereas $O$ is not statistically significant. In contrast, Markowitz et al. (2012), using US samples show that only $O$ and its facets are consistently and positively linked to environmental habits (such as using public transport, carpooling, composting food scraps, recycling, etc.). Regarding the third category, Fraj and Martinez (2006b) use data from Spain and find that $C, A$ and $E$ are positively linked to the actual commitment to environmental engagement (e.g. joining a clean-up drive, attending ecology meetings, and tracking public official voting record on environmental issues).

In this paper, we concentrate on PEB in the second category that includes energy saving and conservation habits that are relatively cheap to implement and do not require large time commitment. In contrast to the EE investment, environmental habits involve relatively little objective risk. However, depending on the habit individuals may evaluate the subjective risk differently. The habits such as switching off the lights when not in use and putting on more clothes instead of raising the thermostat setting are low-risk. Other habits can carry higher perceived risk: some individuals consider a personal car to be more reliable than a bus; a sudden change in weather may make a bike ride uncomfortable or even hazardous. As mentioned above, consumers may consider the EE investments (Fischbacher et al., 2015; Qiu et al., 2014) to carry significant risks. Similarly, there is an uncertainty among consumers regarding the PEB benefits, including personal benefits and the impact on the environment. In addition, risk averse individuals prefer to stick to old habits and defaults and judge them as low risk. Based on that, we hypothesise that risk averse individuals are less likely to engage in PEB (Table 1). 
PEB is positively linked to environmental concern: individuals making environmentally friendly conservation decisions are more concerned about the environment (Czap and Czap, 2010). Along the same lines, Fraj and Martinez (2006a) find that the individuals following ecological lifestyle score higher on the actual commitment subscale mentioned above. However, while environmental concern leads to a higher intent to behave environmentally-friendly, it does not necessarily translate into an actual pro-environmental consumer behaviour (Quintelier, 2014). One of the reasons for this weak link between attitude and action is that environmental concern affects PEB (such as requesting a greenelectricity brochure) indirectly via situation-specific cognitions (Bamberg, 2003). In this paper, we are interested in the role of the stable personality factors in environmental decisions and we posit that personality traits will be mediated by environmental concern in their influence on PEB (see the second set of hypotheses for PEB in Table 1).

\subsection{Data}

To test the hypotheses, we use data from the Understanding Society survey in the UK, the successor of the British Household Panel Survey (BHPS) (University of Essex, 2010, 2014). Since 2009 almost 50,000 households and 100,000 individuals have been interviewed on an annual basis. The survey covers all regions of the UK and is nationally representative. The data contains a wide range of variables, ranging from individual attitudes to household's socio-economic characteristics. It also covers the variables necessary to test the suggested mediation mechanism of personality traits on EE investments and PEB. The latest information on EE is available in Wave 4 (2012-2013), whereas the data on risk preferences and personality traits was collected in Wave 1 (2009-2010) and Wave 3 (2011-2012), respectively. Because the latter two variables were measured in preceding years, we tested whether they are time invariant ${ }^{3}$. We include only owner-occupied households in the analysis

\footnotetext{
${ }^{3}$ For further details, see description of the variables below.
} 
since renters cannot decide on major dwelling adjustments.

EE investments. The data set contains information on whether households installed a solar panel or wind turbine for heating or electricity purposes. We use the answers from Wave 4 on the question "Have you installed or are you seriously considering any of the following": (1) “solar panels for electricity?”, (2) "solar water heating?”, (3) "wind turbine to generate electricity?". Each question has the following answers to choose from: "Yes-fitted", "Yes-seriously considering", "Considered in the past and rejected" and "No". Based on the answers, we derive two dependent variables for EE investments.

The first dependent variable allows us to distinguish between households that have considered an EE investment and those that have not $\left(E E_{C}\right)$. If a household considered any of the adoptions, we code $E E_{C}$ with 1 (for the answers "Yes-fitted", "Yes-seriously considering", "Considered in the past and rejected"), otherwise 0 ("No"). The second dependent variable is conditioned on those households that have considered any of the EE measures and indicates an EE adoption on an ordered categorical scale $\left(E E_{A}\right)$ : "Yes-fitted" (2), "Yes-seriously considering" (1) and "Considered in the past and rejected" (0).

Personality traits. Wave 3 includes questions about the Big Five personality factors: Openness to Experience, Conscientiousness, Extraversion, Agreeableness and Neuroticism. Each personality trait is assessed using three questions. For each question, participants were asked to rate themselves from (1) "does not apply to me at all" to (7) "applies to me perfectly". Because personality traits were not measured in Wave 4, we mapped EE investment figures with traits from Wave 3. We tested for invariance of personality traits and the results show that they can be expected to stay stable over time (Appendix B).

Personality traits are individual characteristics, whereas EE investments are household outcomes. A growing body of evidence suggests that household behaviour does not only reflect the attitudes and decisions of a single individual (e.g. household head), but 
also incorporates the preferences of other household members who participate in the decision-making process (Milfont and Markowitz, 2016; Grossbard, 2011; Donni and Chiappori, 2011). For households with two adults (e.g. couples or a parent living with an adult child), we assume joint decision-making and take their average personality traits and other individual-level characteristics. In case of three or more adults (e.g. multiple-adult households incl./excl. couples, couples with an adult child), we average the attributes of the homeowner responding to the survey and his/her indicated partner ${ }^{4}$. If there is no partner or no data available on the partner, we take the attributes of the responding homeowner only. Since the reviewed EE investments require significant financial outlays, we additionally weigh the attributes of the selected adults by their share of the household income to check for robustness of the results.

Risk preferences. The first channel of the personality traits mediation is risk preference. Wave 1 includes a question that asks for participants' risk attitude. Respondents can choose between answers on an 11-item Likert scale from "I am not prepared to take risks at all" (0) to "I am fully prepared to take risks" (10). Since we are matching risk attitudes from Wave 1 with figures from Wave 4, we tested for invariance of risk attitudes using the data from Wave 1 and BHPS data from 2008 (University of Essex, 2010). The results show that the risk preferences are likely to be stable across a 3 to 4-year timespan, with some tendency to decline with age (Appendix C).

Environmental concern. The second channel of the personality traits mediation is environmental concern. Wave 4 also includes a module related to environmental attitudes. Respondents self-assess their attitudes to environment on a 5-item Likert scale from "strongly agree" (1) to "strongly disagree" (5):

1. "My behaviour and everyday lifestyle contribute to climate change."

\footnotetext{
${ }^{4}$ Partner in this context means the other person in a couple or any other adult indicated by the responding homeowner.
} 
2. "If things continue on their current course, we will soon experience a major environmental disaster."

3. "Climate change is beyond control it's too late to do anything about it."

4. "The effects of climate change are too far in the future to really worry me."

5. "It's not worth me doing things to help the environment if others don't do the same."

6. "It's not worth the UK trying to combat climate change, because other countries will just cancel out what we do."

A lower score ("strongly agree") for the first two questions means a higher environmental concern, whereas for the remaining four questions there is an inverse relationship. We reverse the answers to questions one and two to create a consistent measure, with higher scores indicating greater environmental concern. Subsequently, we averaged the scores to each question to construct an index of environmental concern, $E C$.

Pro-environmental behaviour (PEB). Wave 4 includes questions about PEB, out of which 8 can be categorised as environmental habits that are relatively cheap to implement. Respondents choose an answer on a 5-item scale ranging from "Always" (1) to "Never" (5). We reverse the answers to questions 2 and 4-8 (see below), so that higher scores on the scale correspond to more engagement in PEB. Subsequently, the PEB index was calculated as an average of the answers to:

1. "Leave your TV on standby for the night."

2. "Switch off lights in rooms that aren't being used."

3. "Keep the tap running while you brush your teeth."

4. "Put more clothes on when you feel cold rather than putting the heating on or turning it up."

5. "Take your own shopping bag when shopping."

6. "Use public transport (e.g. bus, train) rather than travel by car."

7. "Walk or cycle for short journeys less than 2 or 3 miles." 
8. "Car share with others who need to make a similar journey."

Control variables. Based on the EE and PEB literature, we include the following control variables into the analyses: income per household member, age, gender, education, and the number of children in a household (Hamilton et al., 2014; Mills and Schleich, 2012; Chen et al., 2011; Nair et al., 2010; Poortinga et al., 2003). We also account for dwelling type (detached/semi-detached/end terrace/terraced house or flat) and control for different solar irradiance levels, which indicate the yearly average solar irradiance per Government Office Region in the $\mathrm{UK}^{5}$. Table 2 presents the summary statistics of the samples.

(Insert Table 2 here)

\subsection{Estimation}

We use structural equation modelling (SEM) assuming no joint-normality (Byrne, 2013) and bootstrap the estimated effects following Preacher and Hayes (2008). EE investments $E E_{i}{ }^{6}$ is the dependent variable. Risk preferences $\left(R_{i}\right)$ and environmental concern $\left(E C_{i}\right)$ depict the mediators, and personality traits $\left(X_{i j}\right)$ are the independent variables with $j=$ $\{1, \ldots, 5\}$ representing the average score of the household partners for Openness to Experience, Extraversion, Conscientiousness, Agreeableness and Neuroticism for each household $i$ (Figure 1).

Path $c_{j}$ in Figure $1 \mathrm{~A}$ is the total effect of $X_{i j}$ on $E E_{i}$. In Figure 1B, it is decomposed into the direct effect $c^{\prime}{ }_{j}$ and the indirect effects of $X_{i j}$ on $E E_{i}$ via the two mediators $R_{i}$ and $E C_{i} . a_{1 j}$ and $a_{2 j}$ depict the effects of $X_{i j}$ on the two mediators, while path $b_{1}$ and $b_{2}$ represent the effects of the mediators on $E E_{i}$. The total indirect effect of $X_{i j}$ on $E E_{i}$ is the

\footnotetext{
${ }^{5}$ The figures for the irradiance levels are taken from http://contemporaryenergy.co.uk/insolation-map/ for Northern Ireland and from http://www.theecoexperts.co.uk/freebook/appendix-solar-insolation-values-uk for the remaining Government Office Regions (accessed on October 3, 2016). ${ }^{6} E E_{i}$ stands for either considerations of EE investments $\left(E E_{C, i}\right)$ or EE adoptions $\left(E E_{A, i}\right)$.
} 
sum of both specific indirect effects $a_{1 j} b_{1}$ and $a_{2 j} b_{2}$.

We estimate two types of models. The first, Model 1 (M1), assumes that the mediation mechanism of personality traits works equally well across different households. The corresponding equations to estimate the coefficients are:

$$
\begin{gathered}
R_{i}=d_{1}+\sum_{j=1}^{5} a_{1 j} X_{i j}+\gamma_{1} Z_{i}+\varepsilon_{i 1} \\
E C_{i}=d_{2}+\sum_{j=1}^{5} a_{2 j} X_{i j}+\gamma_{2} Z_{i}+\varepsilon_{i 2} \\
E E_{i}=d_{3}+\sum_{j=1}^{5} c^{\prime}{ }_{j} X_{i j}+b_{1} R_{i}+b_{2} E C_{i}+\gamma_{3} Z_{i}+\varepsilon_{i 3}
\end{gathered}
$$

where $\gamma_{k} Z_{i}$ denotes the product of the vector for the control variables, $Z_{i}$, with the corresponding coefficient vector $\gamma_{k}, d_{k}$ is the intercept, and $\varepsilon_{i k}$ is the error term for the equations $k=\{1, \ldots, 3\}$. The personality traits, mediators and control variables are standardised due to different scales of the observations.

Model 2 (M2) represents an extension of M1 by introducing household income per household member as a moderator on path $b_{1}$ and $b_{2}$, meaning that coefficients $b_{1}$ and $b_{1}$ are calculated conditionally on income per member $I_{i}$ (Figure 1). The effect of personality traits via the two mediators can be translated only into the decision to seriously consider or undertake an investment if household income is sufficient to afford it. Formally, the third equation is adjusted as follows:

$$
E E_{i}=d_{3}+\sum_{j=1}^{5} c_{j}^{\prime} X_{i j}+b_{1} R_{i}+b_{2} E C_{i}+\gamma_{3} Z_{i}+\beta_{I} I_{i}+\beta_{R I} R I_{i}+\beta_{E C I} E C I_{i}+\varepsilon_{i 3}
$$

where $\beta_{I}$ is the coefficient for income, $\beta_{R I}$ is the coefficient for the product of risk preferences and income, $R I_{i}$, and $\beta_{E C I}$ represents the coefficient for the product of environmental concern and income $E C I_{i}$. 
To estimate the coefficients, a fitting process of the first and second moments (mean and variance) was implemented by applying maximum-likelihood estimation, conditional on the independent values as given (no joint-normality assumption). The assumption of no jointnormality is necessary because dummy and ordered categorical variables are included in the equation system. This allows us to better assess the stability of coefficients in case of nonnormal variables.

To test for significance of the estimated coefficients, $95 \%$ bias-corrected bootstrapping confidence intervals are used. The advantage of bootstrapping is that it does not impose any specific distribution of the coefficients when testing for significance. The bias-corrected confidence intervals account for any skewness and bias present in the distribution of the estimated coefficients ${ }^{7}$.

We apply the same estimation procedure for PEB, excluding solar irradiance and building type as control variables, which are not relevant for this outcome variable.

\section{Results}

The next two sections describe the results of the mediation models M1 and M2 for EE considerations $\left(E E_{C, i}\right)$ and EE adoptions $\left(E E_{A, i}\right)$, followed by the mediation results for PEB.

\subsection{The Big Five and EE investments}

First, we discuss the estimation results of M1. The left-hand part of Table 3 summarises the mediation results of M1 comparing households that have considered an EE investment with those that have not. Notably, the Big Five influence the decision to consider investing in EE through environmental concern, but not through risk preferences. Openness to Experience and Agreeableness both have a positive impact, whereas Extraversion shows a negative effect.

(Insert Table 3 here)

\footnotetext{
${ }^{7}$ For further details about bootstrapping, see Preacher et al. 2007.
} 
To assess which personality traits effectively lead to adoption of EE technology, we estimated M1 only for the households that have considered an investment: (1) the households that adopted EE measures; (2) the households that are currently seriously considering adoption; and (3) the households that considered and rejected (right-hand part Table 3).

In contrast to considering an EE investment, an actual investment is influenced by personality traits through the mediation channel of risk preferences. Openness to Experience and Extraversion increase the probability of investing in EE through risk preferences, whereas Agreeableness and Neuroticism have a negative impact, providing support to 4 out of our 5 hypotheses for risk (Table 1). The absolute size of the effect is the strongest for Openness to Experience (0.0220) and Neuroticism (-0.0224).

For mediation through environmental concern, Openness to Experience shows a positive statistically significant effect on the probability of investing in EE, whereas Extraversion has a negative effect, providing support for 3 out of the 5 hypotheses (Table 1). A possible explanation for an intriguing result that more extroverted individuals are less environmentally concerned is that such individuals are less disturbed by the environmental threats because of their tendency to have positive emotions and an optimistic way of thinking.

Due to the opposing mediation effects through risk preferences and environmental concern, the total indirect effects are not significant with the exception of Openness to Experience.

Overall, we conclude that: (1) the Big Five personality traits indirectly influence consideration of an EE investment through the channel of environmental concern; and (2) the Big Five personality traits indirectly influence EE adoptions through both the risk preferences and environmental concern channels.

Next, we discuss EE investment in the context of income heterogeneity by estimating model M2. In the first step, we test whether income has a significant impact on the translation 
of the mediators by dividing the households into low-income (L), medium-income (M), and high-income groups $(\mathrm{H})$. In the second step, in case income has a significant moderation effect, we run the mediation analyses for M2 and test the differences of the effects between $\mathrm{H}$ and L households for significance. As for M1, we analyse both the decision to consider and the decision to adopt.

Table 4 shows a significantly positive income moderation for risk preferences for the EE adoptions as indicated by the positive and statistically significant interaction term between risk preference and income. However, this interaction is not significant for the decision to consider EE investments. This is expected since considering an EE investment is not associated with a substantial financial outlay and therefore should not depend on financial capacity. There is no statistically significant income moderation for environmental concern for both EE considerations and EE adoptions.

(Insert Table 4 here)

We therefore test M2 only for EE adoptions (Table 5). The results show that except for Conscientiousness, the effects of the Big Five traits are mediated by risk preferences, but not by environmental concern. The differences of these risk mediation effects between $\mathrm{H}$ and L households are statistically significant and indicate a stronger mediation of personality traits for H households (Table 6).

(Insert Table 5 and 6 here)

The results in M2 indicate that higher income can ease the translation of risk preferences into EE adoptions, therefore facilitating the mediation of the personality traits through this channel. In M2, the concern about the environment, however, does not significantly affect the decision to invest in EE once a household has considered such an investment.

As a robustness check, we take the weighted personality traits and other individual- 
level characteristics for households' couples instead of using the averages (according to the individuals' share on households' income) and run the same analyses for M1 and M2. The results are the same in terms of signs and significance of the results, showing only minor differences in the strength of the coefficients. The corresponding tables are available on request.

\subsection{The Big Five and PEB}

The estimation results of M1 with PEB as a dependent variable show that only the mediation effects through environmental concern are significant, but not the effects through risk preferences (Table 7).

\section{(Insert Table 7 here)}

We found support for 5 out of 10 hypotheses (Table 1) regarding the mediation of the Big Five and PEB relationship. The results indicate that there is no risk preference mediation for Conscientiousness, Extraversion, and Neuroticism, but there is a positive mediation for Openness to Experience and Agreeableness by environmental concern. Also, the direct effects for Openness to Experience, Conscientiousness and Extraversion show significant influence and are considerably stronger than the mediating effects, thus indicating a straightforward impact on PEB. Openness to Experience and Extraversion show further significant total effects. Overall, we conclude that: (1) depending on the trait, the Big Five have a direct and indirect influence on the PEB through the channel of environmental concern; and (2) the mediation by risk preferences does not influence the Big Five - PEB relationship.

We also tested whether the mediated effects of the Big Five vary with financial capacity in the context of PEB (M2). The results suggest, however, that there is no significant moderation (Table 4), i.e. income does not significantly ease or reinforce the translation of either risk preference or environmental concern into actual PEB. 


\section{Conclusions and policy implications}

This paper set out to empirically investigate whether the propensity to engage in green behaviours, such as investments in domestic energy efficiency (EE), can be explained by the decision-maker's personality traits. The analysis of the UK household panel data shows that personality traits, as measured by the Big Five, are indeed significant predictors of EE investments and other less costly pro-environmental behaviours (PEBs). Openness to Experience, Extraversion and Agreeableness influence the probability of considering and making high-cost EE investments and engaging in PEB. Neuroticism shows associations with PEB and realisations of EE investments, whereas Conscientiousness influences PEB only.

Besides providing an insight on the impact of personality traits on PEB, this study suggests that personality traits contribute to the explanation of households' heterogeneity with respect to one-time high-cost EE investments. The importance of personality traits for environmental engagement is, therefore, not only manifested in habitual green activities but also in infrequent high-cost decisions that are driven by more deliberate thinking. Hence, personality traits should be acknowledged as one of the many possible determinants of green decisions, such as convenience, norms, ideological and socio-economic factors among others (Hamilton et al., 2014; Allcott and Rogers, 2014; Peattie, 2001).

We found that personality traits influence decisions to consider investments in EE through environmental concern. Risk preferences, on the other hand, have a principal function for the mediation of personality traits in the case of implementation of EE measures. A personality trait constellation that results in high risk preference and high environmental concern increases the likelihood of investing in EE. If either risk preference or environmental concern are low, the likelihood of EE investment depends on the strength of the corresponding effects. If personality trait profiles are expressed in both low risk preference and low environmental concern, EE investments are unlikely. This offers a potential reason 
for the EE gap, in addition to the commonly observed market imperfections (e.g. lack of information).

Given the crucial role of risk attitudes in a household's decision to implement EE measures and that it is virtually impossible to change personality traits, we suggest that a greater emphasis should be placed on risk-sharing and risk reduction when developing government policies and private-sector investment products. Risk reduction can be achieved by increasing the range of lending products for EE measures that are currently offered by liquidity providers. Such loans can be tailored to mitigate the risk in EE projects by using floating interest rates linked to energy prices (i.e. decline/increase in energy prices leads to downward/upward adjustment of the interest rate). Furthermore, the strength of the link between energy prices and interest rate (i.e. the hedge) can be varied. Offering a variety of lending products, appealing to different risk preference profiles, would increase the uptake of EE investments.

Since personality traits also affect EE decisions through environmental concern, they can similarly guide the design of pro-environmental programmes. According to energy conservation studies, direct provision of information does not lead to significant changes in energy saving behaviour (Steg, 2016). Thus, we propose that, instead of simply informing people about environmental issues, policy makers and environmental organisations should customise their messages to different target audiences. For instance, since Openness to Experience influences EE considerations and investments through environmental concern, eco-labels could be designed with visual effects that engage with the typical openness facets of inner feelings and emotions. Alevizou et al. (2015) argue that consumers are not proficient in reading standard eco-labels such as Blue Angel, Nordic Swan, and EU Daisy, but “they have a right to truthful, useful and substantiated on-pack information” (p. 8743). Along these lines and based on this study we propose that instead of using alphabetical letters or figures 
of carbon emissions, the levels of EE on eco-labels could be visualised with pictures ranging from polluted cities (low EE) to green landscapes (high EE). Such visualisations might be more effective for openness-prone people than just highlighting the financial value of energy savings. Such visualisations will also help communicate more saliently the environmental impact of products (in our case EE), the need for which has been identified by Alevizou et al. (2015).

The EE results further reveal that the mediation of personality traits through risk preference depends on the level of the household income. In particular, this mediation effect is stronger for wealthier households. This suggests that the individuals with certain personality profiles could be motivated to invest into EE if sufficient financial incentives (e.g. governmental subsidies, tax breaks) are made available.

With regard to the low-cost $\mathrm{PEB}$, the findings broadly fall in line with those of previous studies of environmental habits. We find a positive relationship (indirect through environmental concern and total) between Openness to Experience and PEB, as observed by Markowitz et al. (2012) and Brick and Lewis (2014). We further observe a positive direct effect of Conscientiousness consistent with the study of Brick and Lewis. While Milfont and Sibley's (2012) Study 2 on electricity conservation actions suggests a total positive impact for Conscientiousness, Agreeableness and Neuroticism, our findings suggest indirect effects of the latter two traits through environmental concern and a total negative impact of Extraversion instead. A possible explanation for the difference in findings is the difference in the model specification, time of data collection and geography (UK vs. New Zealand). The negative impact of Extraversion on PEB further differs to the positive relationship found by Brick and Lewis. The contradicting finding might be due to differences in the PEB measures: Brick and Lewis include activities related to routine purchases (e.g. buying organic/local 
food), which are possibly more appealing to extraverts and their more impulsive and broader range of activities compared to other environmental habits, such as switching off lights.

For PEB, the main mediator of personality traits is environmental concern with some traits exerting a direct impact. In contrast to the effects of EE investments, the coefficients for PEB sensitivity to personality traits do not depend on income level. Thus, policy-makers should capitalise on the sensitivities of PEB to personality traits through environmental concern by making the impact of PEB more salient. This can be done, for instance, by displaying the savings from switching off the lights on the light switch or by displaying the savings from keeping the temperature down by 1 degree on the thermostat.

Overall, our study demonstrates that personality traits may pose another barrier on the way to achieve energy reduction goals in the residential sector. Differentiated and targeted products and policies informed by such behavioural insights are crucial for encouraging higher levels of residential EE investments and PEB. 


\section{References}

Allcott, H., \& Greenstone, M. (2012). Is there an energy efficiency gap? The Journal of Economic Perspectives, 26, 3-28.

Allcott, H., \& Mullainathan, S. (2010). Behavior and Energy Policy. Science, 327, 12041205.

Allcott, H., \& Rogers, T. (2014). The short-run and long-run effects of behavioral interventions: Experimental evidence from energy conservation. American Economic Review, 104, 3003-37.

Alevizou, P., Oates, C. \& McDonald, S. (2015). The well(s) of knowledge: The decoding sustainability claims in the UK and Greece. Sustainability 7(7), 8729-8747; doi:10.3390/su7078729.

Bamberg, S. (2003). How does environmental concern influence specific environmentally related behaviors? A new answer to an old question. Journal of Environmental Psychology, 23, 21-32.

Bardhan, A., Jaffee, D., Kroll, C., \& Wallace, N. (2014). Energy efficiency retrofits for U.S. housing: Removing the bottlenecks. Regional Science and Urban Economics 47, 4560.

Borghans, L., Heckman, J.J., Golsteyn, B.H.H., \& Meijers, H. (2009). Gender differences in risk aversion and ambiguity aversion. Journal of the European Economic Association, 7, 649-658.

Brick, C., \& Lewis, G.J. (2014). Unearthing the "green" personality: Core traits predict environmentally friendly behavior. Environment and Behavior. doi:10.1177/0013916514554695.

Brown, S., \& Taylor, K. (2014). Household finances and the "Big Five" personality traits. Journal of Economic Psychology, 45, 197-212. 
Byrne, B. M. (2013). Structural equation modeling with AMOS: Basic concepts, applications, and programming. Routledge.

Caliendo, M., Fossen, F., \& Kritikos, A.S. (2014). Personality characteristics and the decisions to become and stay self-employed. Small Business Economics, 42, 787-814.

Chen, X., Peterson, M., Hull, V., Lu, C., Lee, G.D., Hong, D., \& Liu, J. (2011). Effects of attitudinal and sociodemographic factors on pro-environmental behaviour in urban China. Environmental Conservation, 38, 45-52.

Chui, A.C., Titman, S., \& Wei, K.J. (2010). Individualism and momentum around the world. The Journal of Finance, 65, 361-392.

Cobb-Clark, D.A., Schurer, S., 2012. The stability of big-five personality traits. Economics Letters $115,11-15$.

Committee on Climate Change (2014). Buildings factsheet. Report. Committee on Climate Change (CCC).

Costa, P.T., \& MacCrae, R.R. (1992). Revised NEO Personality Inventory (NEO PI-R) and NEO Five-Factor Inventory (NEO FFI): Professional manual. Psychological Assessment Resources.

Czap, N.V., \& Czap, H.J. (2010). An experimental investigation of revealed environmental concern. Ecological Economics, 69, 2033-2041.

Czap, N.V., Czap, H.J., Khachaturyan, M., Lynne, G.D., \& Burbach, M. (2012). Walking in the shoes of others: Experimental testing of dual-interest and empathy in environmental choice. The Journal of Socio-Economics, 41, 642-653.

De T'Serclaes, P. (2010). Money matters: Mitigating risk to spark private investments in energy efficiency. OECD, IEA.

Donni, O., \& Chiappori P.-A. (2011). Nonunitary models of household behavior: A survey of the literature. In Molina, J. A. (Ed.), Household Economic Behaviors (pp. 1-40). New 
York: Springer.

Directive 2006/32/EC of the European Parliament and of the Council of 5 April 2006 on energy end-use efficiency and energy services and repealing Council Directive 93/76/EEC (2006). Official Journal of the European Union, L 114/64.

Directive 2012/27/EU of the European Parliament and of the Council of 25 October 2012 on energy efficiency, amending Directives 2009/125/EC and 2010/30/EU and repealing Directives 2004/8/EC and 2006/32/EC (2012). Official Journal of the European Union, L 315/1.

Epper, T., Fehr-Duda, H., \& Schubert, R. (2011). Energy-Using Durables: The Role of Time Discounting in Investment Decisions. IED Working paper 11-16. IED Institute for Environmental Decisions, ETH Zurich.

Fischbacher, U., Schudy, S., \& Teyssier, S. (2015). Heterogeneous Preferences and Investments in Energy Saving Measures. Discussion Paper 2015-11. Münchener Wirtschaftswissenschaftliche Beiträge, Ludwig Maximilian University of Munich.

Fletcher, J.M. (2013). The effects of personality traits on adult labor market outcomes: Evidence from siblings. Journal of Economic Behavior \& Organization, 89, 122-135.

Fraj, E., \& Martinez, E. (2006a). Environmental values and lifestyles as determining factors of ecological consumer behaviour: an empirical analysis. Journal of Consumer Marketing, 23, 133-144.

Fraj, E., \& Martinez, E. (2006b). Influence of personality on ecological consumer behaviour. Journal of Consumer Behaviour, 5, 167-181.

Gerarden, T.D., Newell, R.G., \& Stavins, R.N. (2015). Assessing the Energy-Efficiency Gap. NBER Working Paper No. 20904. National Bureau of Economic Research.

Gherzi, S., Egan, D., Stewart, N., Haisley, E., \& Ayton, P. (2014). The meerkat effect: Personality and market returns affect investors portfolio monitoring behaviour. 
Journal of Economic Behavior \& Organization, 107, Part B, 512-526.

Goswami, D. Y., \& Kreith, F. (2007). Energy Conversion. CRC Press.

Grossbard, S. (2011). Independent individual decision-makers in household models and the New Home Economics. In Molina, J. A. (Ed.), Household Economic Behaviors (pp. 41-56). New York: Springer.

Hamilton, I.G., Shipworth, D., Summerfield, A.J., Steadman, P., Oreszczyn, T., \& Lowe, R. (2014). Uptake of energy efficiency interventions in English dwellings. Building Research \& Information, 42, 255-275.

Harvey, F. (2014). UK should have 10 million homes with solar panels by 2020, experts say. The Guardian, January 29. http://www.theguardian.com/environment/2014/jan/29/uk10-million-homes-solar-panels-2020 (accessed on October 12, 2016).

Hilbig, B.E., Zettler, I., Moshagen, M., \& Heydasch, T. (2013). Tracing the path from personality - via cooperativeness - to conservation: Honesty-humility and ecological behaviour. European Journal of Personality, 27, 319-327.

Hirsh, J.B. (2010). Personality and environmental concern. Journal of Environmental Psychology, 30, 245-248.

Hirsh, J.B., \& Dolderman, D. (2007). Personality predictors of consumerism and environmentalism: A preliminary study. Personality and Individual Differences, 43, $1583-1593$

Lange, I., Moro, M., \& Traynor, L. (2014). Green hypocrisy?: Environmental attitudes and residential space heating expenditure. Ecological Economics, 107, 76-83.

Linares, P., \& Labandeira, X. (2010). Energy efficiency: economics and policy. Journal of Economic Surveys, 24, 573-592.

Markowitz, E.M., Goldberg, L.R., Ashton, M.C., \& Lee, K. (2012). Profiling the "proenvironmental individual”: A personality perspective. Journal of Personality, 80, 81- 
111.

Mihet, R. (2013). Effects of culture on firm risk-taking: a cross-country and cross-industry analysis. Journal of Cultural Economics, 37, 109-151.

Milfont, T.L., \& Markowitz, E. (2016). Sustainable consumer behavior: a multilevel perspective. Current Opinion in Psychology, 10, 112-117.

Milfont, T.L., \& Sibley, C.G. (2012). The big five personality traits and environmental engagement: Associations at the individual and societal level. Journal of Environmental Psychology, 32, 187-195.

Mills, B., \& Schleich, J. (2012). Residential energy-efficient technology adoption, energy conservation, knowledge, and attitudes: An analysis of European countries. Energy Policy, 49, 616-628.

Milojev, P., \& Sibley, C. G. (2014). The stability of adult personality varies across age: evidence from a two-year longitudinal sample of adult New Zealanders. Journal of Research in Personality, 51, 29-37.

Nair, G., Gustavsson, L., \& Mahapatra, K. (2010). Factors influencing energy efficiency investments in existing Swedish residential buildings. Energy Policy, 38, 2956-2963.

Obschonka, M., Schmitt-Rodermund, E., Silbereisen, R.K., Gosling, S.D., \& Potter, J. (2013). The regional distribution and correlates of an entrepreneurship-prone personality profile in the United States, Germany, and the United Kingdom: A socioecological perspective. Journal of Personality and Social Psychology, 105, 104.

Obschonka, M., Stuetzer, M., Gosling, S.D., Rentfrow, P.J., Lamb, M.E., Potter, J., \& Audretsch, D.B. (2015). Entrepreneurial regions: Do macro-psychological cultural characteristics of regions help solve the "knowledge paradox" of economics? PloS one, 10, e0129332. doi:10.1371/journal.pone.0129332.

Ovchinnikova, N.V., Czap, H.J., Lynne, G.D., \& Larimer, C.W. (2009). “I don’t want to be 
selling my soul": Two experiments in environmental economics. The Journal of Socio-Economics, 38, 221-229.

Peattie, K. (2001). Golden goose or wild goose? The hunt for the green consumer. Business Strategy and the Environment, 10, 187-199.

Pérez-Lombard, L., Ortiz, J., \& Velázquez, D. (2013). Revisiting energy efficiency fundamentals. Energy Efficiency, 6, 239-254.

Poortinga, W., Steg, L., Vlek, C., \& Wiersma, G. (2003). Household preferences for energysaving measures: A conjoint analysis. Journal of Economic Psychology, 24, 49-64.

Preacher, K.J., \& Hayes, A.F. (2008). Asymptotic and resampling strategies for assessing and comparing indirect effects in multiple mediator models. Behavior research methods, 40, 879-891.

Preacher, K.J., Rucker, D.D., \& Hayes, A.F. (2007). Addressing moderated mediation hypotheses: Theory, methods, and prescriptions. Multivariate behavioral research, 42, $185-227$.

Ramos, A., Gago, A., Labandeira, X., \& Linares, P. (2015a). The role of information for energy efficiency in the residential sector. Frontiers in the Economics of Energy Efficiency, 52, Supplement 1, S17-S29.

Ramos, A., Labandeira, X., \& Löschel, A. (2015b). Pro-environmental Households and Energy Efficiency in Spain. Environmental and Resource Economics, 63, 367-393.

Ryan, L., Selmet, N., \& Aasrud, A. (2012). Plugging the energy efficiency gap with climate finance, In International Energy Agency Insights Series 2012. IEA. Paris, France.

Qiu, Y., Colson, G., \& Grebitus, C. (2014). Risk preferences and purchase of energyefficient technologies in the residential sector. Ecological Economics, 107, 216-229.

Quintelier, E. (2014). The influence of the Big 5 personality traits on young people's political consumer behavior. Young Consumers, 15, 342-352. 
Steg, L. (2016). Behaviour: Seeing heat saves energy. Nature Energy, 1, 15013.

Stern, P. C., Janda, K. B., Brown, M. A., Steg, L., Vine, E. L., \& Lutzenhiser, L. (2016). Opportunities and insights for reducing fossil fuel consumption by households and organizations. Nature Energy, 1, 16043.

Swami, V., Chamorro-Premuzic, T., Snelgar, R., \& Furnham, A. (2010). Egoistic, altruistic, and biospheric environmental concerns: A path analytic investigation of their determinants. Scandinavian Journal of Psychology, 51, 139-145.

UNFCCC, United Nations Framework Convention on Climate Change (2015). Paris Agreement. http://unfccc.int/paris_agreement/items/9444.php (Accessed on May 27, 2017).

University of Essex (2010). ISER, British Household Panel Survey: Waves 1-18, 1991-2009. 7th Edition. UK Data Service. SN: 5151

University of Essex (2014). ISER, NatCen Social Research and Kantar Public: Understanding Society: Waves 1-4, 2009-2013. 6th Edition. Colchester, Essex: UK Data Service, November 2014. SN: 6614.

Young, W., Hwang, K., McDonald, S., \& Oates, C.J. (2010). Sustainable consumption: green consumer behaviour when purchasing products. Sustainable Development, 18, 20-31.

Zhao, H., Seibert, S.E., \& Lumpkin, G.T. (2010). The relationship of personality to entrepreneurial intentions and performance: A meta-analytic review. Journal of Management, 36, 381-404. 
Tables and figures

Table 1: Hypotheses

\begin{tabular}{lcccc}
\hline & \multicolumn{2}{c}{ EE investment } & \multicolumn{2}{c}{ PEB } \\
& $\mathrm{R}$ & $\mathrm{EC}$ & $\mathrm{R}$ & $\mathrm{EC}$ \\
\hline Openness to Experience & + & + & + & + \\
Conscientiousness & - & $0 /+$ & $0 /-$ & + \\
Extraversion & + & 0 & 0 & 0 \\
Agreeableness & - & + & - & + \\
Neuroticism & - & 0 & 0 & 0 \\
\hline
\end{tabular}

Note: This table presents the hypotheses for the mediation of the Big Five traits through risk preferences (R) and environmental concern (EC) on energy efficiency (EE) investment and pro-environmental behaviour (PEB), respectively (+/-/0: positive/negative/neutral relationship). 


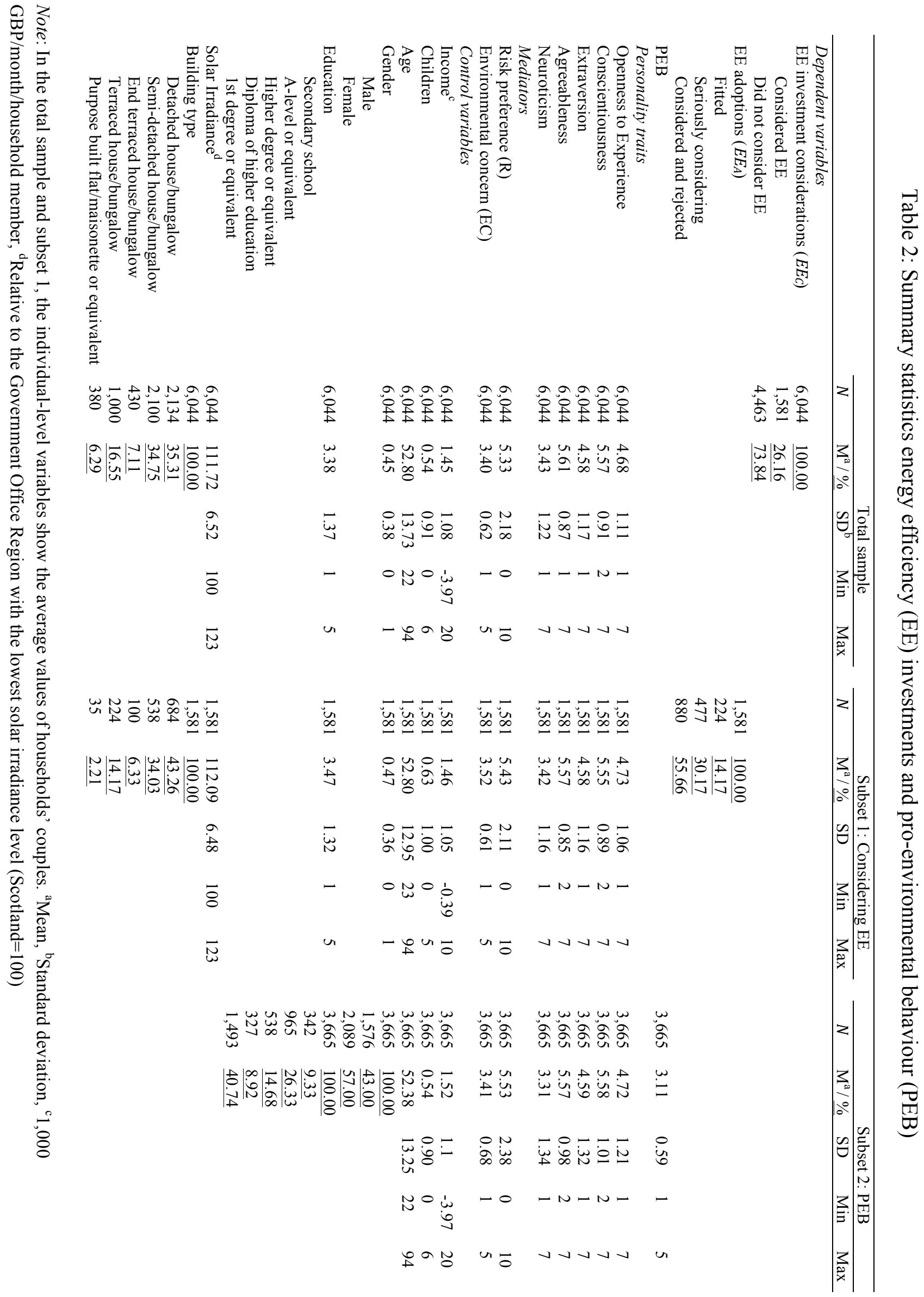




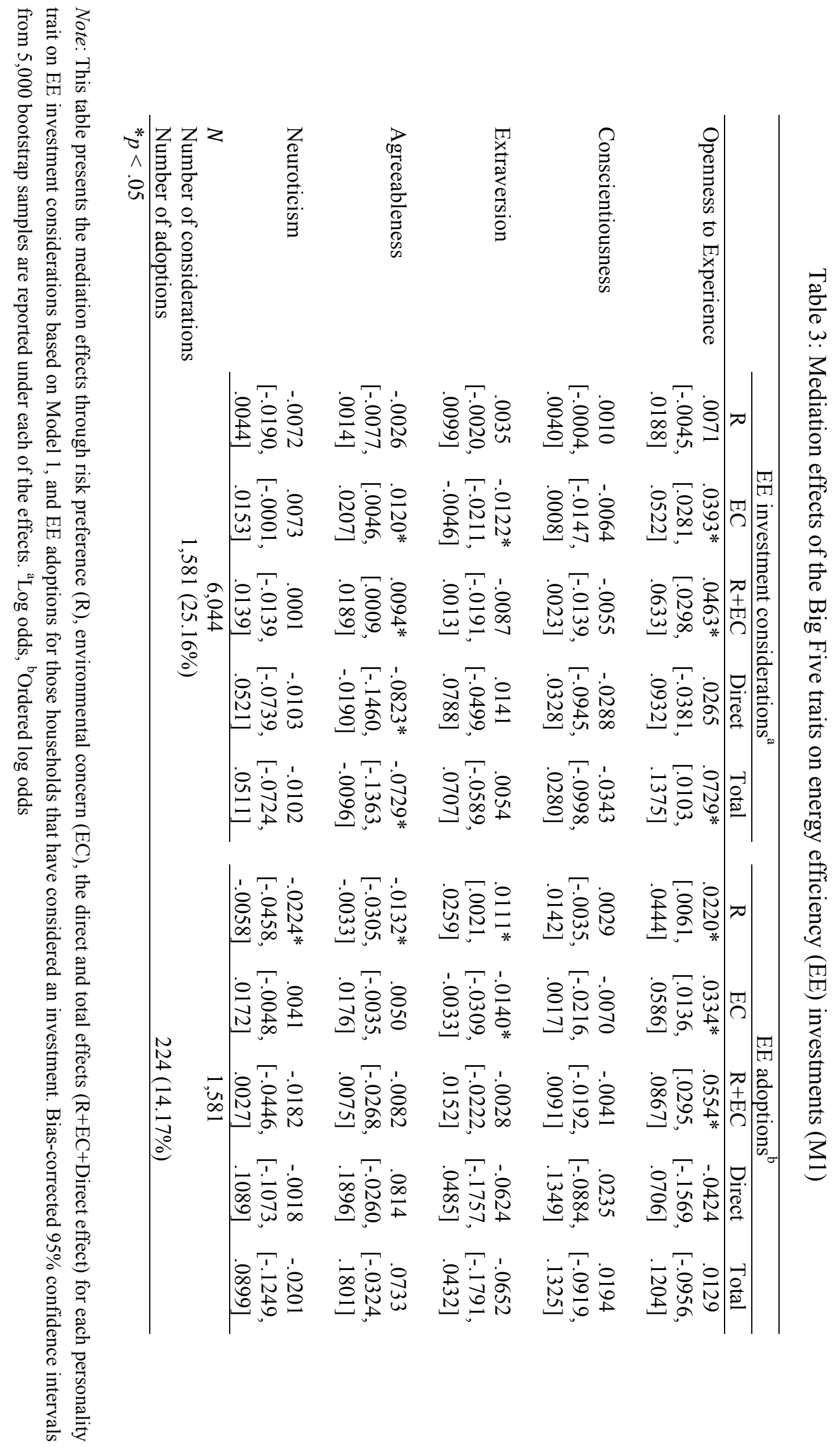


Table 4: Moderation effects of household income on energy efficiency (EE) investments and pro-environmental behaviour (PEB) (M2)

\begin{tabular}{|c|c|c|c|}
\hline & $\begin{array}{l}\text { EE investment } \\
\text { considerations }{ }^{\mathrm{a}}\end{array}$ & EE adoptions ${ }^{b}$ & PEB \\
\hline \multicolumn{4}{|l|}{ Personality traits } \\
\hline Openness to Experience & .0262 & -.0402 & $.0233^{* *}$ \\
\hline Conscientiousness & -.0286 & .0232 & $.0228 * *$ \\
\hline Extraversion & .0153 & -.0647 & $-.0277 * * *$ \\
\hline Agreeableness & $-0.0817 * *$ & .0823 & -.0106 \\
\hline Neuroticism & -.0108 & .0006 & -.0094 \\
\hline \multicolumn{4}{|l|}{ Mediators } \\
\hline Risk preference (R) & .0852 & -.1725 & -.0198 \\
\hline Environmental concern (EC) & $.1776^{* *}$ & .0620 & $.0896 * * *$ \\
\hline \multicolumn{4}{|l|}{ Moderators } \\
\hline Income_cat ${ }^{\mathrm{c}}$ x R & -.0715 & $.4940^{* *}$ & .0147 \\
\hline Income_cat ${ }^{\mathrm{c}} \times \mathrm{EC}$ & .2320 & .2955 & .0530 \\
\hline \multicolumn{4}{|l|}{ Control variables } \\
\hline Income_cat $^{\mathrm{c}}$ & -.1782 & -.5049 & $-.0912 *$ \\
\hline Children & $.1225 * * *$ & .0713 & $-.0364 * * *$ \\
\hline Age & .0363 & $-.1324 * *$ & $.0890 * * *$ \\
\hline Gender & $.1576^{*}$ & .1189 & $-.0740 * * *$ \\
\hline Education & .0084 & .0229 & $.0620 * * *$ \\
\hline Solar irradiance & $.0900 * * *$ & -.0320 & \\
\hline Building type & $-.2519 * * *$ & $-.2682 * * *$ & \\
\hline$N$ & 6,044 & 1,581 & 3,665 \\
\hline Log-likelihood $^{\mathrm{d}}$ & $-19,771.86$ & $-5,781.49$ & $-13,082.87$ \\
\hline
\end{tabular}

Note: ${ }^{\mathrm{a}} \mathrm{Log}$ odds, ${ }^{\mathrm{b}}$ Ordered log odds, ${ }^{\mathrm{c}} \mathrm{Low}-/$ medium-/high-income group $(\mathrm{L} / \mathrm{M} / \mathrm{H})$ by approximately the same number of households per group, ${ }^{\mathrm{d}} \mathrm{Log}$-likelihood of the full equation model (including the regressions for risk preference and environmental concern), ${ }^{*} \mathrm{p}<.10,{ }^{* *} \mathrm{p}<.05,{ }^{* * *} \mathrm{p}<.01$ 


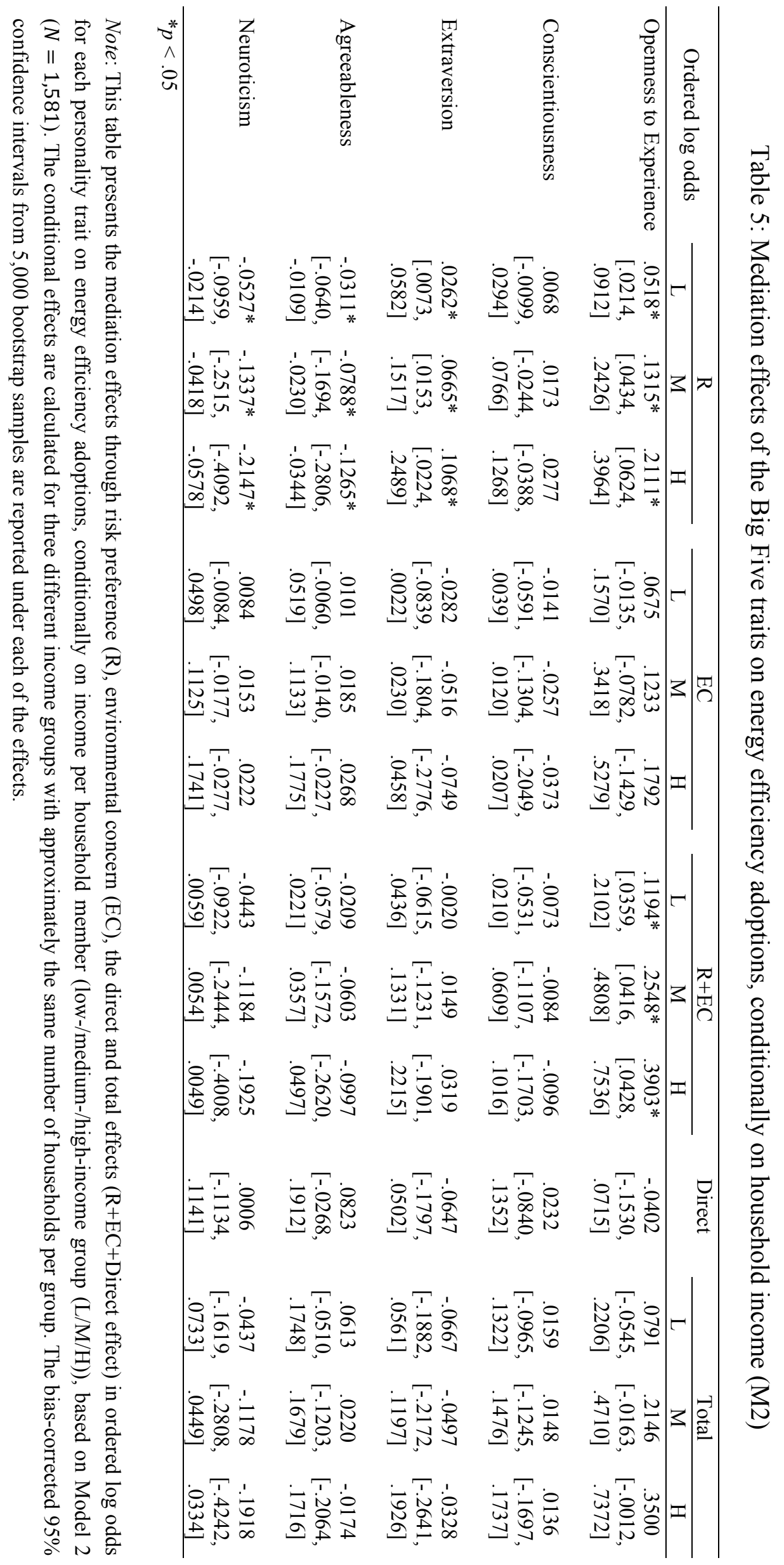


Table 6: Differences of risk preference mediation effects between high-income and lowincome households for energy efficiency adoptions

\begin{tabular}{lc}
\hline & $\Delta \mathrm{R}$ \\
\hline Openness to Experience & $.1593^{*}$ \\
Conscientiousness & {$[.0375, .3050]$} \\
& .0209 \\
Extraversion & {$[-.0269, .0989]$} \\
& $.0805^{*}$ \\
Agreeableness & {$[.0152, .1946]$} \\
& $-.0954^{*}$ \\
Neuroticism & {$[-.2185,-.0217]$} \\
& $-.1620^{*}$ \\
\hline$* p<.05$ & {$[-.3219,-.0340]$} \\
\hline
\end{tabular}

Note: This table presents the differences of the risk preference mediation effects for each personality trait on energy efficiency adoptions between high-income $(\mathrm{H})$ and low-income $(\mathrm{L})$ households in ordered log odds $(\Delta \mathrm{R})$, based on Model $2(N=1,581)$. Bias-corrected 95\% confidence intervals from 5,000 bootstrap samples are reported under each of the differences.

Table 7: Mediation effects of the Big Five traits on pro-environmental behaviour (M1)

\begin{tabular}{lccccc}
\hline & $\mathrm{R}$ & $\mathrm{EC}$ & $\mathrm{R}+\mathrm{EC}$ & $\mathrm{Direct}$ & Total \\
\hline Openness to & -.0016 & $.0145^{*}$ & $.0129^{*}$ & $.0232^{*}$ & $.0362^{*}$ \\
Experience & {$[-.0050, .0017]$} & {$[.0103, .0192]$} & {$[.0076, .0186]$} & {$[.0037, .0438]$} & {$[.0162, .0565]$} \\
Conscientiousness & .0001 & $-.0049^{*}$ & $-.0048^{*}$ & $.0227^{*}$ & .0178 \\
& {$[-.0002, .0010]$} & {$[-.0087,-.0011]$} & {$[-.0087,-.0010]$} & {$[.0034, .0423]$} & {$[-.0015, .0377]$} \\
Extraversion & -.0012 & $-.0040^{*}$ & $-.0052^{*}$ & $-.0278^{*}$ & $-.0330^{*}$ \\
& {$[-.0037, .0013]$} & {$[-.0081,-.0001]$} & {$[-.0100,-.0006]$} & {$[-.0475,-.0080]$} & {$[-.0528,-.0130]$} \\
Agreeableness & .0007 & $.0069^{*}$ & $.0076^{*}$ & -.0107 & -.0031 \\
& {$[-.0007, .0024]$} & {$[.0030, .0112]$} & {$[.0034, .0121]$} & {$[-.0302, .0094]$} & {$[-.0224, .0181]$} \\
Neuroticism & .0020 & $.0040^{*}$ & $.0060^{*}$ & -.0097 & -.0037 \\
& {$[-.0022, .0061]$} & {$[.0002, .0081]$} & {$[.0003, .0117]$} & {$[-.0291, .0100]$} & {$[-.0233, .0163]$} \\
\hline
\end{tabular}

$* p<.05$

Note: This table presents the mediation effects through risk preference (R), environmental concern (EC), the direct and total effects ( $\mathrm{R}+\mathrm{EC}+$ Direct effect) for each personality trait on pro-environmental behaviour, based on Model $1(N=3,665)$. Bias-corrected $95 \%$ confidence intervals from 5,000 bootstrap samples are reported under each of the effects. 
Figure 1: Mediation model M1 and moderated mediation M2

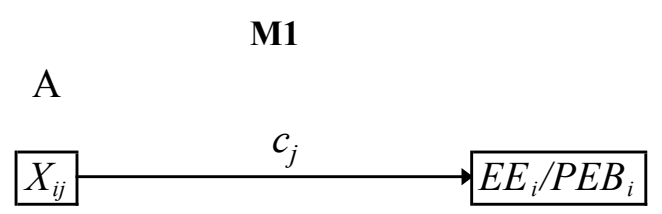

B
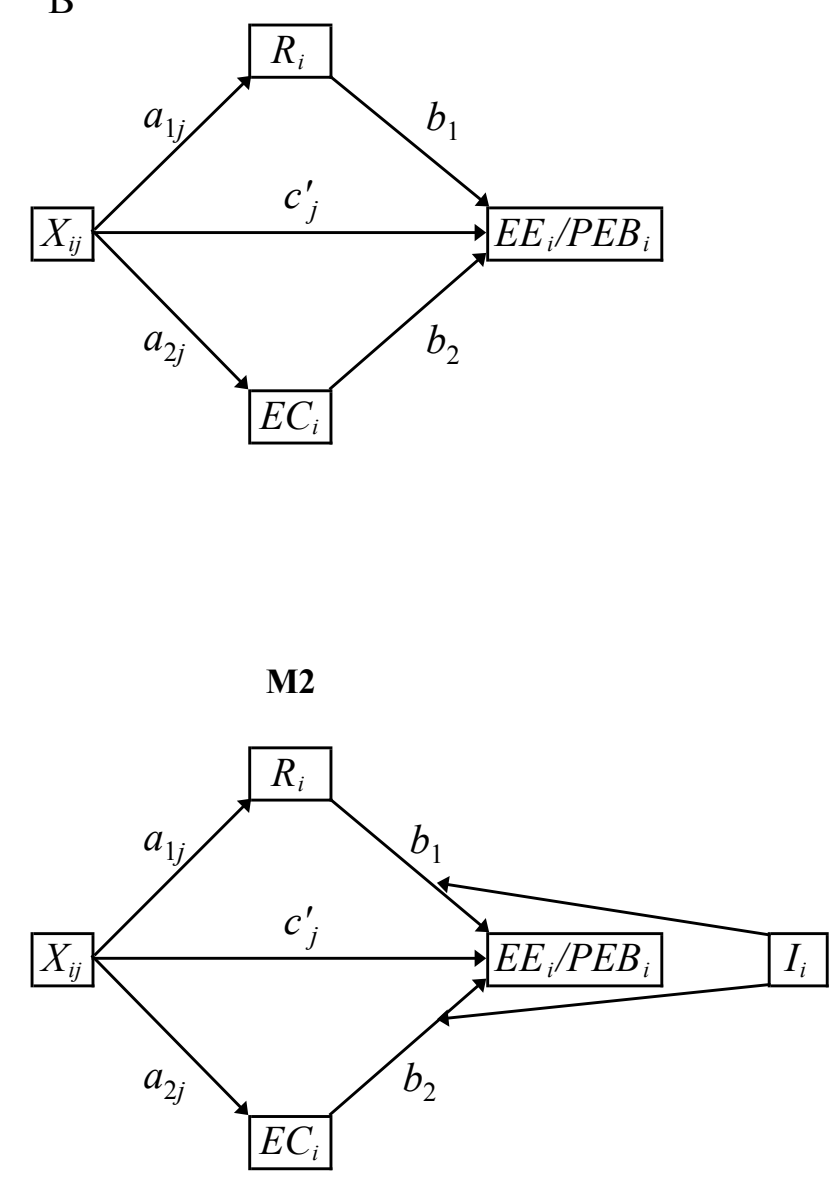

Note: Models of the Big Five traits $\left(X_{i j}\right.$ with $j=$ \{Openness to Experience, Conscientiousness, Extraversion, Agreeableness, Neuroticism $\}$ ) mediation through risk preferences $\left(R_{i}\right)$ and environmental concern $\left(E C_{i}\right)$ on energy efficiency (EE) investments $\left(E E_{i}\right)$ and pro-environmental behaviour $\left(P E B_{i}\right)$, where $i$ denotes the households and $I_{i}$ is the income per household member. 


\section{Appendix A Energy conservation and EE}

Energy conservation and EE might seem to be closely related at the first sight. Both can save energy. However, one important difference is that energy conservation is inevitably associated with a reduction in service demand, whereas EE can save energy while holding service demand constant (Pérez-Lombard et al., 2013). Typical energy conservation measures include reducing indoor temperature, turning off lights or cycling instead of using a car.

It is less clear what can be considered energy-efficient. The unclarity arises because the term "EE" is used by different research disciplines and it involves two components — it is defined as the ratio of output (performance, service, goods, energy) to energy input (De T’Serclaes, 2010; Directive 2012/27/EU).

From an engineering point of view, higher EE means higher energy conversion, i.e. the same energy input (e.g. solar, geothermal) can be converted to more final energy (e.g. electricity), or less energy input is required for the same amount of final energy (Goswami and Kreith (2007)). For example, HVAC (Heating, Ventilating, Air- Conditioning) systems with better conversation rates are considered more energy-efficient.

In the context of renewable sources, a system is considered more energy-efficient if energy input from exhaustible resources (e.g. fossil fuels) is reduced and service is held constant. Examples include “on-site" renewables, such as solar panels for electricity generation installed at building sites, which source energy directly from the environment and reduce energy dependence from the supply side (Pérez-Lombard et al., 2013).

EU legislation considers improved passive energy systems (e.g. thermal insulation, window glazing) and active forms - technology that transforms energy (e.g. refrigerators, lightings) — as eligible EE measures, including renewable systems that reduce energy input from the supply side: “(g) domestic generation of renewable energy sources, whereby the amount of purchased energy is reduced (e.g. solar thermal applications, domestic hot water, 
solar-assisted space heating and cooling)" (Energy Service Directive (ESD), Annex III, Directive 2006/32/EC).

Since there is no unique definition of EE, we integrate the different explanations as done by Pérez-Lombard et al. (2013) and consider passive energy technology (e.g. wall insulation), and energy from renewable resources that is generated "on-site" (i.e. does not have to be delivered to the consumer) and that simultaneously reduces purchased energy, to be energy-efficient (e.g. solar electricity, geothermal heating).

\section{Appendix B. Stability of personality traits}

We checked the stability of personality traits following Cobb-Clark and Schurer (2012) and Brown and Taylor (2014). While there are other, more sophisticated approaches using structural equation models (e.g. the analysis of the developmental patterns in the stability of personality traits by Milojev and Sibley (2014)), we opted for the mean-level method as it allows us to efficiently assess the stability of personality traits across time rather than looking into developmental patterns across age. Our dataset contains 7,554 participants for whom we were able to match the Big Five responses in BHPS-2005 and in Wave 3 (20112012) of Understanding Society (University of Essex, 2010, 2014). The average responses for each trait are presented in the third and fourth column of Table B. For each individual, we constructed the measure of the change in a personality trait as $\Delta \operatorname{Trait}_{j}^{i}=\operatorname{Trait}_{j 2011}^{i}-$ $\operatorname{Trait}_{j 2005}^{i}$, where $i$-individual, $j=$ Openness to Experience, Conscientiousness, Extraversion, Agreeableness, and Neuroticism. Each of the Big Five traits is measured on the 7-point scale, which implies that the difference can range from -6 to 6 . The mean change ranges from 0.149 to 0.198 with a standard deviation of about 1 . The mean proportional change is very low: between $1.59 \%$ and $6.64 \%$. The median of the change $\left(50^{\text {th }}\right.$ percentile $)$ is zero. This suggests that the personality traits measured by Big Five remain stable for a period of at least 6 years. This result is consistent with the conclusions of the Cobb-Clark and Schurer (2012) 
study using the Australian Household, Income and Labour Dynamics survey and of the Brown and Taylor (2014) study using the British Household Panel Survey and the Understanding Society datasets. The coefficients of longitudinal correlation reported in the second column of Table B and the respective t-statistics provide an additional confirmation of stability of traits: all correlation coefficients are significant at $0.001 \%$.

Table B: Stability of personality traits

\begin{tabular}{|c|c|c|c|c|c|c|c|c|c|c|c|}
\hline & \multirow{3}{*}{$\begin{array}{l}\text { Coefficient of } \\
\text { correlation } \\
\text { (t-stat) }\end{array}$} & \multirow{2}{*}{\multicolumn{2}{|c|}{$\begin{array}{l}\text { Level } \\
\text { Mean }\end{array}$}} & \multicolumn{8}{|c|}{ Changes between 2005 and 2011} \\
\hline & & & & \multirow[b]{2}{*}{ Mean } & \multirow[b]{2}{*}{ St. dev. } & \multirow[b]{2}{*}{$\%$ change } & \multicolumn{5}{|c|}{ Percentile of distribution } \\
\hline & & 2005 & 2011 & & & & $1^{\text {st }}$ & $25^{\text {th }}$ & $50^{\text {th }}$ & $75^{\text {th }}$ & $99^{\text {th }}$ \\
\hline Openness to Experience & $0.549(57.2)$ & 4.490 & 4.464 & -0.028 & 1.151 & 4.57 & -3.000 & -0.667 & 0.000 & 0.667 & 3.000 \\
\hline Conscientiousness & $0.463(45.4)$ & 5.291 & 5.495 & 0.198 & 1.079 & 6.64 & -2.667 & -0.333 & 0.000 & 0.667 & 3.000 \\
\hline Extraversion & $0.590(63.5)$ & 4.477 & 4.603 & 0.123 & 1.079 & 6.37 & -2.667 & -0.667 & 0.000 & 0.667 & 3.000 \\
\hline Agreeableness & $0.475(47.0)$ & 5.450 & 5.624 & 0.175 & 0.982 & 5.41 & -2.333 & -0.333 & 0.000 & 0.667 & 2.667 \\
\hline Neuroticism & $0.604(65.9)$ & 3.683 & 3.538 & -0.149 & 1.182 & 1.59 & -3.000 & -1.000 & 0.000 & 0.667 & 3.000 \\
\hline
\end{tabular}

\section{Appendix C. Stability of risk preferences}

Unfortunately, there is no British longitudinal data on risk preference that would allow us to perform stability analysis of risk preference over 3-4 years similar to personality traits (Cobb-Clark and Schurer, 2012; Brown and Taylor, 2014). Instead, we have to explore the differences in risk preferences between different ages and try to make inferences of what will happen as people get 3-4 years older. We have the risk data for BHPS-2008 (Wave 18) and Understanding Society-2009 (US-2009) (University of Essex, 2010, 2014). We are interested in whether/how their risk preference changed by 2012. In both datasets we find negative and statistically significant at $1 \%$ correlation between age and risk, meaning that as people age, they become more risk averse.

In the 2008 dataset, the ages of the respondents vary 15-99 years and in the 2009 dataset, the ages vary 16-98. We cut the ages which have less than 10 observations, which left us with the range of 15-91 in 2008 and 16-94 in 2009. For each age, we calculated the mean risk preference. After that we calculated the difference between the mean scores of people 4 
and 3 years apart in the 2008 and 2009 datasets, respectively, to bring them to 2012:

$\Delta \overline{R l s k}_{g}^{2008}=\overline{R l s k}_{g}^{2008}-\overline{R l s k}_{g-4}^{2008}$ and $\Delta \overline{R l s k}_{g}^{2009}=\overline{R l s k}_{g}^{2009}-\overline{R l s k}_{g-3}^{2009}$, where $g$ is the age of the participant. This is done under the assumption that risk preferences will change by the average difference in risk preferences between the age groups 3 years and 4 years apart in 2008 and 2009, respectively.

As evident from the second and third rows of Table $\mathrm{C}$, the mean differences in risk attitudes are quite small in absolute and relative value (\% change). In over $75 \%$ of the age groups, the risk preference is lower for older people. We performed a similar analysis on the subset of US-2009 that we are using in the model. After removing the age groups with less than 10 observations, we were left with the range of 26-87 years old. In this subset, the difference in the risk preference is even smaller than in the full sample (see the fourth row of Table C). We conclude that the risk preferences are likely to be stable across the period of 3-4 years with some tendency to go down as people age.

Table C: Stability of risk preferences

\begin{tabular}{|c|c|c|c|c|c|c|c|c|c|c|}
\hline & \multirow{2}{*}{$\begin{array}{l}\text { Difference } \\
\text { in years }\end{array}$} & \multirow{2}{*}{$\begin{array}{c}\# \text { of } \\
\text { observations }\end{array}$} & \multirow{2}{*}{$\begin{array}{c}\text { Mean } \\
\text { difference }\end{array}$} & \multirow{2}{*}{$\begin{array}{l}\text { Standard } \\
\text { deviation }\end{array}$} & \multirow{2}{*}{$\begin{array}{c}\% \\
\text { change }\end{array}$} & \multicolumn{5}{|c|}{ Percentiles } \\
\hline & & & & & & $1 \mathrm{st}$ & 25 th & 50 th & 75 th & 99th \\
\hline BHPS-2008 & 4 & 12,714 & -0.145 & 0.297 & -2.441 & -0.836 & -0.331 & -0.160 & -0.008 & 0.632 \\
\hline US-2009 & 3 & 39,419 & -0.124 & 0.243 & -2.368 & -0.680 & -0.244 & -0.098 & -0.010 & 0.616 \\
\hline $\begin{array}{l}\text { Subset of } \\
\text { US-2009 }\end{array}$ & 3 & 6,044 & -0.081 & 0.470 & -1.095 & -1.187 & -0.387 & -0.108 & 0.121 & 1.051 \\
\hline
\end{tabular}

